\title{
Navorsingswerk en spesialiteitsgebiede in die Departement Elektriese en Elektroniese Ingenieurswese aan die Universiteit van Pretoria
}

\author{
I.K. Craig \\ Departement Elektriese en Elektroniese Ingenieurswese, Universiteit van Pretoria, 0002. E-pos: icraig@postino.up.ac.za
}

Ontvang + November 1998; aanvaar + Februarie 1999

\section{UITTREKSEL}

Die artikel gee 'n oorsig van die navorsingswerk wat in die Departement Elektriese en Elektroniese Ingenieurswese aan die Universiteit van Pretoria gedoen word. Sewe navorsingsvelde, nl. bio-ingenieurswese, elektriese energie, elektromagnetisme, mikro-elektronika. meet en heheer, patroonherkenning, en seine en telekommunikasie, bestaan in die departement. Navorsing wat in hierdie velde gedoen word, word kortliks beskryf aan die hand van 'n beskrywing van die akliwiteite en huidige projekte; onlangse navorsingsuitselte word ook gelys.

\begin{abstract}
Research and areas of speciality in the Department of Electrical and Electronic Engineering at the University of Pretoria This article gives an overview of the research performed in the Department of Electrical and Electronic Engineering at the University of Pretoria. Research is undertaken in seven areas, i.e. Bio-engineering, Electrical Energy, Electromagnetism, Micro-electronics, Measurement and Control, Pattern recognition, and Signals and Telecommunications. Research in these areas is briefly described, and a list of current projects are given logether with a sample of recent research outputs.
\end{abstract}

\section{INLEIDING}

Die Departement Elektriese en Elektroniese Ingenieurswese aan die Universiteit van Pretoria is die grootste ingenieursdepartement in die land met 30 doserende personeel (22 met Ph.D.-grade), 575 voorgraadse en 183 nagraadse studente. Die departement beskik oor 'n bewese navorsingskapasiteit. Elf van die doserende personeel beskik oor SNO-graderings, terwyl 'n verdere vier aansoeke onlangs ingedien is vir die SNO se eweknie-evaluering.

Navorsing in die departement word in groepsverband in die volgende sewe velde gedoen: bio-ingenieurswese, elektriese energie, elektromagnetisme, mikro-elektronika, meet en beheer, patroonherkenning, en seine en telekommunikasie. Meer toegespitste navorsing word d.m.v. die Carl Emily Fuchs Instituut vir Mikro-elektronika en verskeie sentrums gedoen, waaronder die Alcatel Research Unit for Wireless Access, die Sentrum vir Nuwe Elektrisiteitstudies, die Sentrum vir Elektromagnetisme, die Sentrum vir Televerkeer-Ingenieurswese vir die Inligtingsamelewing, die Nokia Sentrum in Sellulêre Telefonie, en die Sentrum vir Radio- en Syferkommunikasie.

In hierdie artikel word die aktiwiteite van die departement in die verskeie navorsingsvelde bespreek. 'n Verkorte lys van onlangse navorsingsuitsette word gegee en illustreer die kwaliteit en kwantiteit van die departement se navorsingsaktiwiteite. Verdere inligting kan verkry word vanaf www.ee.up.ac.za/ intro.html.

\section{BIO-INGENIEURSWESE}

\section{Opsomming van aktiwiteite}

Die aktiwiteite van die bio-ingenieurswesegroep is gerig op navorsing en ontwikkeling in drie velde, naamlik: rehabilitasieingenieurswese, biomediese seinverwerking en die modellering van biologiese stelsels. Rehabilitasie-ingenieurswese fokus op die ontwikkeling van vindingryke elektroniese hulpmiddels vir gestremdes. Aktiwiteite in biomediese seinverwerking sluit in EEG-analise met behulp van neurale netwerke, EMG-analise vir spierkragbepaling en analise van verskeie fisiologiese aanwysers van stres en uitputting. In biologiese stelselmodellering is die fokus op die modellering van menslike stres, die bio-akoestiek van gehoor, die biomeganika van asemhaling en ander fisiologiese beheerstelsels.

\section{Lys van huidige projekte}

- Rekenaargesteunde parameterskatting vir longfunksiediagnose tydens meganiese ventilasie van babas.

- Analise van stroomverspreiding rondom multi-elektrodeskikkings vir kogleêre prosteses.

- Ontwikkeling van multikanaal inplanteerbare RF-telemetrie en seinverwerking vir senuweestimulasie.

- Optiese oogposisie-volgstelsel.

- Informasieteoretiese analise van die psigoakoestiese gevolg van elektriese stimulasie en spesifieke keuses van seinverwerkingsalgoritmes van multikanaal kogleêre prosteses.

- Multidimensionele bepaling van menslike uitputting by langafstandvragmotorbestuurders.

- Analise van die menslike velimpedansie en die korrelasie daarvan met interne orgaanpatologie.

- Modellering van die biomeganiese aspekte van nie-indringende bloeddrukmeting.

\section{Onlangse publikasies}

- Hanekom, T. \& Hanekom, J.J. (1998). On the design of implantable electrodes for electrical nerve stimulation, $S . A f r$. J. Sc. , 94, 307-310.

- Hanekom, T., Hanekom, J.J. \& Marais, P. (1998). Actively deposited ceramic layers as insulation on thin implantable electrode conductors, S. Afr. J. Sc., 94, 310-311.

- Hanekom, J.J. \& Shannon, R.V. (I998). Gap detection as a measure of electrode interaction in cochlear implants, $J$. Acoust. Soc. Am., 84(4), 2372-2384.

\section{ELEKTRIESE ENERGIE} Opsomming van aktiwiteite

Die Elektriese-energiegroep bestudeer die opwekking, verspreiding en aanwending van elektriese energie, en fokus spesifiek op 


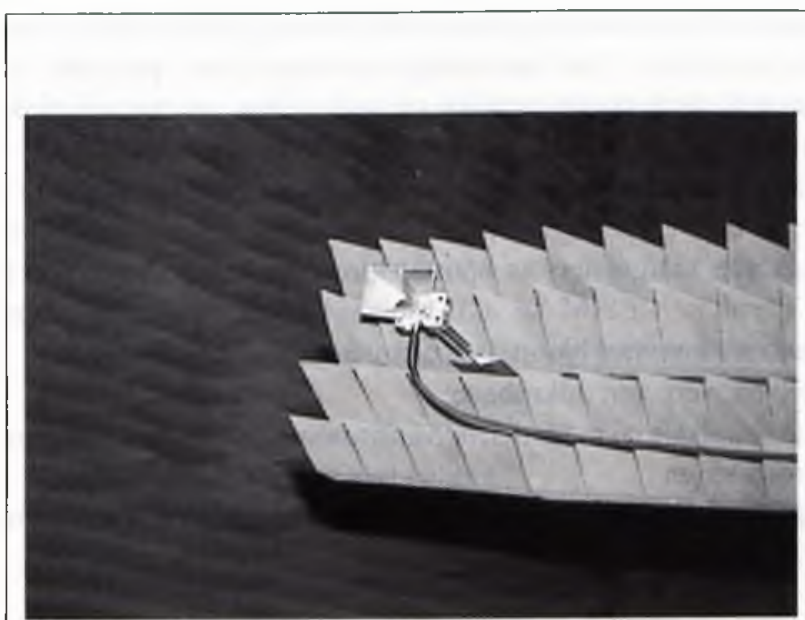

Figuur I: Intennametings in die Kompakte Meethaun.

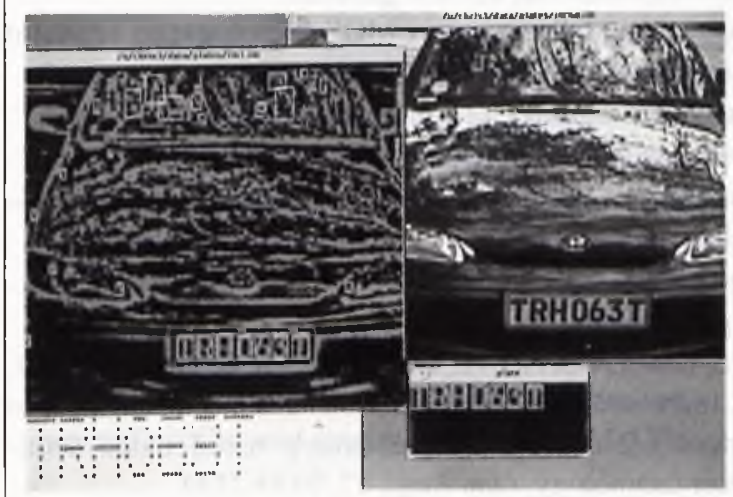
Markov-modelle.
Figuur 2: Motornommerplaat-herkenning met verskuilde

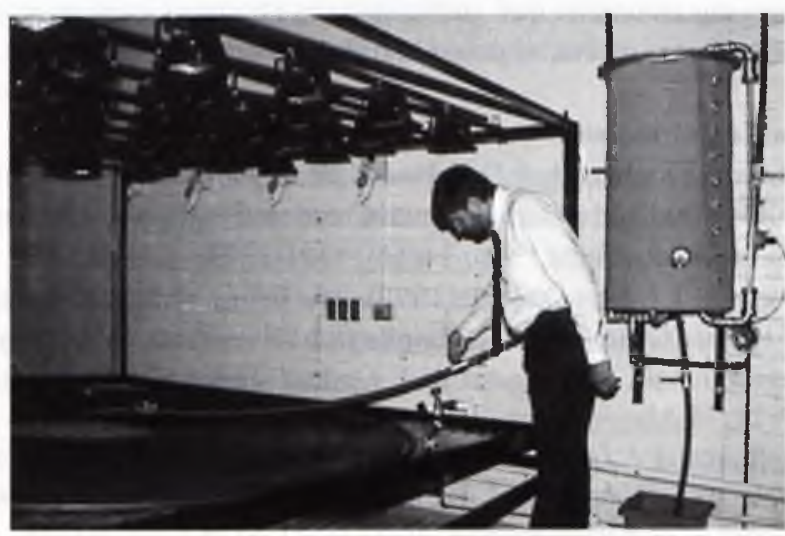

Figuur 3: Son-elektriese wamnaterverhittingstelsel

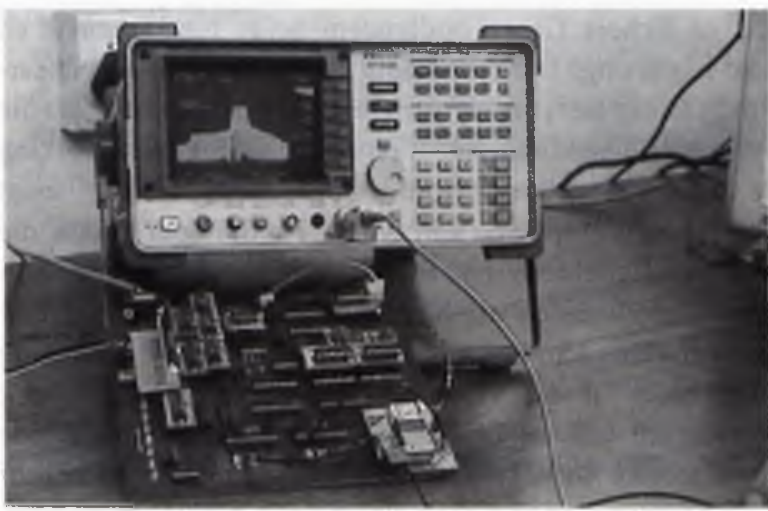

Figuur 4: Enkelsyband-direktesekwensie-spreispektrumsender.

Electr. Eng., 89(2), 56-63.

elektriese lasmodellering en energiebeheer, die komponente van elektriese kragstelsels, betroubaarheid van kragstelsels en die kwaliteit van elektriese toevoer.

Elektriese lasmodellering en energiebeheer word deur die Sentrum vir Nuwe Elektrisiteitstudies (SNES) gedoen. Die SNES het die volgende missiestelling: "Om die koste-effektiewe benutting en voorsiening van elektrisiteit te bevorder deur navorsing, dienslewering en mannekragontwikkeling." Die aktiwiteite van SNES word gereeld deur "n advieskomitee geevalueer om te bepaal of ' $n$ aanvaarbare bydrae gemaak word tot die bevrediging van Suider-A frikaanse behoeftes.

\section{Lys van huidige projekte}

- Universiteit van Pretoria Energiebeleid.

- Energiebestuur by tersiêre instellings (Africampus).

- Lasprofiel-samestelling vir die Munisipaliteit van Pretoria.

- Lasprofiel-databasis.

- Onkonvensionele toepassings van hoërendement elektriese kragopwekkers.

- Kinetiese kragopwekker.

\section{Onlangse publikasies}

- Pretorius, H.M. \& Delport, G.J. (1998). Scheduling of cogeneration systems in response to real-time pricing, Trans. $S$ 1fr. Inst. Electr. Ling., 89(2), 48-55.

- Endrejat. F. \& Delport, G.J. (1998). Modelling of a fin-fan cooler system with variable speed drives, Trans. S. Afr. Inst
- Gitau, M.N.\& Enslin, J.H.R.(1998). PWM Switching strategy with reduced harmonic injection for bush converters, Trans: S. Afr. Inst. Electr. Eng, 89(2), 64-72.

\section{ELEKTROMAGNETISME}

\section{Opsomming van aktiwiteite}

Die groep is aktief in navorsing in die sintese en analise van antennas, passiewe mikrogolf- en millimetergolf-komponente, berekening van elektromagnetiese verstrooiing, elektromagnetiese beeldvorming, HF/BHF/UHF-voortplanting, elektromagnetiese versoenbaarheid en numeriese elektromagnetisme. Die groep het toegang tot spesiale meetfasiliteite, wat die Kompakte Antennameetbaan van die Universiteit van Pretoria insluit. Die Kompakte Antennameetbaan is in 1990 gevestig, en het die vermoë om metings uit te voer in die frekwensiegebied $2-18 \mathrm{GHz}$. Antennas en verstrooiers van tot $2 \mathrm{~m} \times 2 \mathrm{~m} \times 1,2 \mathrm{~m}$ kan gemeet word.

Lys van huidige projekte

- Ontwerp van wyeband-koppelaars en differensiële faseskuiwers.

- Ontwerp en analise van ongelyke golfleier-drywingsverdelers.

- Analise van sirkulêr-gepolariseerde golfleier-gleufstralers.

- Die analise van dubbelweerkaatser-antennas.

- Elektromagnetiese versoenbaarheid-meettegnieke. 
- Die ontwikkeling van ionosferiese voorspellingsmodelle vir intydse kommunikasietoepassings.

- Ontwerp en analise van golfleier-na-mikrostrook-oorgange.

- Sintese van lineêre, vlak- en konforme-samestellings.

\section{Onlangse publikasies}

- Abele, J., Joubert, J. \& Odendaal, J.W. (1998). Introduction of multiple nulls in otherwise onmidirectional pattern of circular dipole array, Electr. Lett., 34(14), 1371-1373.

- Coetzee, J.J. \& Joubert, J. (1998). The Effect of the Inclusion of Higher Order Internal Coupling on Waveguide Slot Array Performance, Microwave and Optical Technology Letters, 17(2), 76-81.

- Malherbe, J.A.G. (1998). An Array of Coupled Nonradiative Dielectric Waveguide Radiators, IEEE Transactions on intennas and Propagation, 46(8), 1121-1125.

\section{MEET EN BEHEER}

\section{Opsomming van aktiwiteite}

Die Meet en Beheer Groep onderneem beide fundamentele en toegepaste navorsing. Die toepassing en evaluering van beheeren outomatisasiestelsels vir industriële prosesse vorm deel van die groep se navorsingsaktiwiteite. Navorsing, wat in samewerking met die industrie gedoen word, word aangemoedig, sodat wesenlike probleme opgelos kan word. Vir dié doel beskik die groep oor kundigheid in outomatisasie-infrastruktuur, stelselidentifikasie, robuuste en nie-lineêre beheer, en die implementering en evaluering van beheerstelsels. Fundamentele navorsing word onderneem in die velde van nie-lineêre beheer asook besluitneming en beheer. In die fundamentele navorsingsvelde word nuwe teorieè ontwikkel, asook die modellering en beheer van nie-holonomiese en vervaardigingstelsels bestudeer.

\section{Lys van huidige projekte}

- Die ontwikkeling van Suid-A frikaanse industriële beheertoepassings-gevallestudies.

- Afgasbeheer vir 'n elektriese boogoond.

- Temperatuurbeheer in die sekondêre verkoelingsone van 'n stringgietmasjien.

- Dikte en spanningsbeheer van plaat in 'n Steckel-warmwalsmasjien.

- Die modellering, beheer en navigasie van 'n rollende skyf, 'n voertuig met 3 sleepwaens, en 'n rollende bal.

- Terugvoerbeheer vanaf metings vir nie-lineêre stelsels wat insluit: inset-uitset-linearisering, ontkoppeling van steurings, stabilisering m.b.v. uitset-terugvoer.

- Digitale kommunikasiestelsels vir veldinstrumentasie.

\section{Onlangse publikasies}

- Camisani-Calzolari, F.R., Craig, I.K. \& Pistorius, P.C. (1998). Specification framework for control of the secondary cooling zone in continuous casting, /SIJ International, 38(5), 447-453.

- Yavin, Y. \& Frangos, C. (1998). Navigation and Control of a Motion of a Rolling Disk Carrying a Controller Translational Moving Rod, J. Frankl. I., 335B(5), 897-914.

- Yavin, Y. (1998). The Control of the Motion of a Pantograph, Mathl. Comput. Modeling, 28(2), 13-23.

\section{MIKRO-ELEKTRONIKA}

\section{Opsomming van aktiwiteite}

Navorsing in dié veld word behartig deur die Carl Emily Fuchs Instituut vir Mikroëlektronika (CEFIM). CEFIM doen reeds die afgelope 15 jaar navorsing en spesialisopleiding op die gebied van mikroëlektronika. Die navorsings- en nagraadse program is hoofsaaklik gerig op die ontwerp van mikrobane, en dan spesifiek die ontwerp van analoog-seinprosesseerders in die CMOStegnologie. Die simulasie en modellering van stroombane, komponente en vervaardigingsprosesse word ook nagevors. Die gebruik van halfgeleiers as opto-elektroniese komponente speel ook 'n rol in CEFIM se aktiwiteite. Die navorsingsprogram konsentreer hoofsaaklik op die volgende aspekte:

- Die ontwerp van mikrobane;

- die simulasie en modellering van stroombane, komponente en prosesse, en

- opto-elektroniese toepassings van silikonkomponente en mikrobane.

\section{Lys van huidige projekte}

- Laetoevoerspanning CMOS-analoogstroombane.

- Laeruis CMOS-logika vir digitale/analoog gemengde stroombane.

- Nuwe konfigurasie van CMOS-geheues.

- Simulasie en modellering van CMOS-tegnologie.

- Neurale netwerke in CMOS-tegnologie.

- Silikon as bron en detektor van optiese seine.

- Innoverende CMOS-komponente.

- Multiwaarde CMOS-logika- en programmeerbare CMOSboublokke.

\section{Onlangse publikasies}

- Snyman, L.W., A haroni, H., Du Plessis, M. \& Gouws, R.B.J. (1998). Increased efficiency of silicon light-emitting diodes in a standard 1.2 micron complementary metal oxide semiconductor technology, Opt. Eng., 37, 2133-2141.

- Seevinck, E., Du Plessis, M., Joubert, T-H. \& Theron, A.E. (1998). Active-bootstrapped gain-enhancement technique for circuits, IEEE Trans. CAS II, 45(9), 1250-1254.

- Snyman, L.W., Aharoni, H. \& Du Plessis, M. (1998). Characterization of breakdown phenomena in light emitting silicon $n+p$ diodes, J. Appl. Phys., 84(5), 2953-2959.

\section{PATROONHERKENNING}

\section{Opsomming van aktiwiteite}

Die groep spesialiseer in toepassings van patroonherkenning en neurale netwerke. Die belangrikste toepassings is in spraakverwerking: hoofsaaklik spraakherkenning vir Suid-A frikaanse tale en aksente en akoestiese fonetiese studies wat hierdie tegnologie komplementeer. Ander toepassingsvelde is beeldverwerking, beeldanalise en radar-teikenherkenning. Teoretiese en implementeringsaspekte van neurale netwerke word ook ondersoek.

\section{Lys van huidige projekte}

Die spesifieke navorsingsaktiwiteite van die groep word in die lys van huidige projekte weerspieël:

\section{Spraaktegnologie}

- Aanpassing van akoestiese modelle tussen tale vir vinnige ontwikkeling van spraakherkenningstelsels.

- Aanpassing van spraakherkenningstegnologie vir SuidAfrikaanse tale met klapklanke.

- Outomatiese herkenning van Afrikaanse foneme in kontinue spraak.

- Outomatiese deteksie van emosionele spanning in 'n spraaksein. 
- 'n Outomatiese spraakherkenning-gebaseerde telefoonsentrale met 'n Afrikaanse gespreksintervlak.

- 'n Akoestiese analise van verskille in die uitspraak van tweedetaal-Engels in Suid-A frika.

- 'n Spraakintervlak vir 'n voorvlug-inligtingstelsel vir vlieëniers.

Beeldanalise en reikenherkenning

- Outomatiese analise van menslike gedragspatrone in 'n "Smart Room"-omgewing.

- Gesigherkenning en -verifikasie.

- Beeldanalise vir teikenherkenning

- Motornommerplaat-herkenning met verskuilde Markovmodelle.

\section{Neurale newwerke}

- Verbetering van optimering in die afrigting van neurale netwerke.

- Afrigtingsalgoritmes vir terugvoer neurale netwerke.

\section{Onlangse publikasies}

- Botha, E.C., Odendaal, J.W. \& Geggus, K.M. (1998). Aircraft down-range profiles formed from simulated and compactrange backscatter, Microwave and Optical Technology letlers, 17(3), 207-213.

- Vermaak, J.\& Botha, E.C. (1998). Recurrent neural networks for short-term load forecasting, IEEE Trans. Power Syst, 13(1), 126-132.

- Coetzee, L. \& Botha, E.C. (1998). The parallel downhill simplex algorithm for unconstrained optimisation, Concurrency: Practice and Experience, 10(2), 121-137.

\section{SEINE- EN TELEKOMMUNIKASIE}

\section{Opsomming van aktiwiteite}

Spesialisnavorsing en konsultasie word in die volgende sentrums beoefen:

CDRC (Centre for Radio and Digital Communication). CDMAtegnieke word ontwikkel vir verbeterde hibriede toegangsmetodes vir multimedia sellulêre telekommunikasiestelsels. Toepassingsareas sluit in:

- CDMA-spreisekwensies.

- Digitale modulasieskemas met 'n spektrale effektiwiteit van 3bis/s/Hz.

- HF/VHF/UHF-kanaalsimulators.

- Toepassing van FPGA's in die ontwikkeling van generiese boublokke vir telekommunikasiestelsels.

ARUWA (Alcatel Research Unit for Wireless Access). Draadlose toegangsmetodes word ontwikkel vir toekomstige nuwe (mobiele) telekommunikasiestelsels. Toepassingsareas sluit in:

- Sellulêre CDMA/TDMA/FDMA

- SDMA-stelsels

- PCN-Radionetwerke

- Binnenshuise draadlose kommunikasie

- Draadlose lokale-lus (WLL)

SETIIS (Sentrum vir Televerkeeringenieurswese vir die Inligtingsamelewing). Die sentrum word in samewerking met die Universiteit van die Noorde (Dept. Rekenaarwetenskap) bedryf. Navorsingsareas in Televerkeeringenieurswese sluit in:

- Modellering van breëbandnetwerke en ook internettoepassings.

- Verkeersbestuur in ATM-netwerke.

- Verkeersvoorspelling op netwerke.
- Impak van XDSL op toekomstige netwerke.

Nokia Sentrum in Sellulere Telefonic. Die Sentrum word in samewerking met die Universiteit van die Noorde (Dept. Rekenaarwetenskap) bedryf. Navorsingsareas in sellulêre kommunikasie sluit in:

- Netwerkbestuur en -optimisering.

- Metings en voorspelling van elektromagnetiese voortplanting vir die optimisering van stelselwerkverrigting.

- Karakterisering van SMS-data en die toekomstige impak van GPRS op die kapasiteit van 'n sellulêre netwerk.

Informasie- en Netwerksekerheid. Die ontwikkeling van veilige kommunikasie oor die internet. Aktiwiteite sluit die volgende in:

- Ontwerp en analise van kriptografiese algoritmes.

- Ontwikkeling van kriptografiese protokolle vir die internet vir die volgende:

- Verifikasie van die sender en die ontvanger se identiteit.

- Boodskapintegriteit.

- Uitruil van geheime sleutels vir veilige kommunikasie.

\section{Onlangse publikasies}

- Jamil, M., Linde, L.P., Cilliers, J.E. \& Van Wyk, D.J. (1998). Comparison of complex spreading sequences based on filtering methods and mean square correlation characteristics, Trans. S. Afr. Inst. Electr. Eng, 89(3), 98-112.

- Swarts, F., Swarts, J.S. \& Lötter, M.P. (1998). Performance evaluation of some basic ARQ schemes in the presence of multiple user interference, Trans. S. Afr: Inst. Electr. ling. 89(3), 158-166.

- Lötter, M.P. \& Van Rooyen, P. (1998). An overview of Space Division Multiple Access techniques in Cellular systems, Trans. S. Afr. Inst. Electr. Eng., 89(3), 176-183.

\section{SUMMARY}

This article gives an overview of the research performed in the Department of Electrical and Electronic Engineering at the University of Pretoria. This department is the largest engineering department in South A frica with 30 faculty members (of which 22 have Ph.D.-degrees), 575 undergraduate and 183 postgraduate students. The research capacity of the department is illustrated by the fact that 11 faculty members have obtained FRD ratings, with a further 4 awaiting the results of this peer-evaluation process. A sample of recent research outputs that are given in this article is indicative of the level and quality of the research.

Research is undertaken in seven areas, i.e. Bio-engineering, Electrical Energy, Electromagnetism, Micro-electronics, Measurement and Control, Pattern recognition, and Signals and Telecommunications. More focussed research is done by the Carl Emily Fuchs Institute for Micro-electronics and various centres, i.e. the Alcatel Research Unit for Wireless Access, the Centre for New Electricity Studies, the Centre for Electromagnetism, the Centre for Tele-traffic Engineering, the Nokia Centre for Cellular Telephony, and the Centre for Radio and Digital Communication.

This article describes the activities of the department in the above mentioned research fields. For each group, a list of current projects is given together with a sample of recent research outputs. Additional information can be obtained from www.ee.up.ac.za intro.html.

\section{BEDANKINGS}

Die outeur bedank kollegas in die Departement Elektriese en Elektroniese Ingenieurswese aan die Universiteit van Pretoria vir hul hulp in die samestelling van die artikel. 


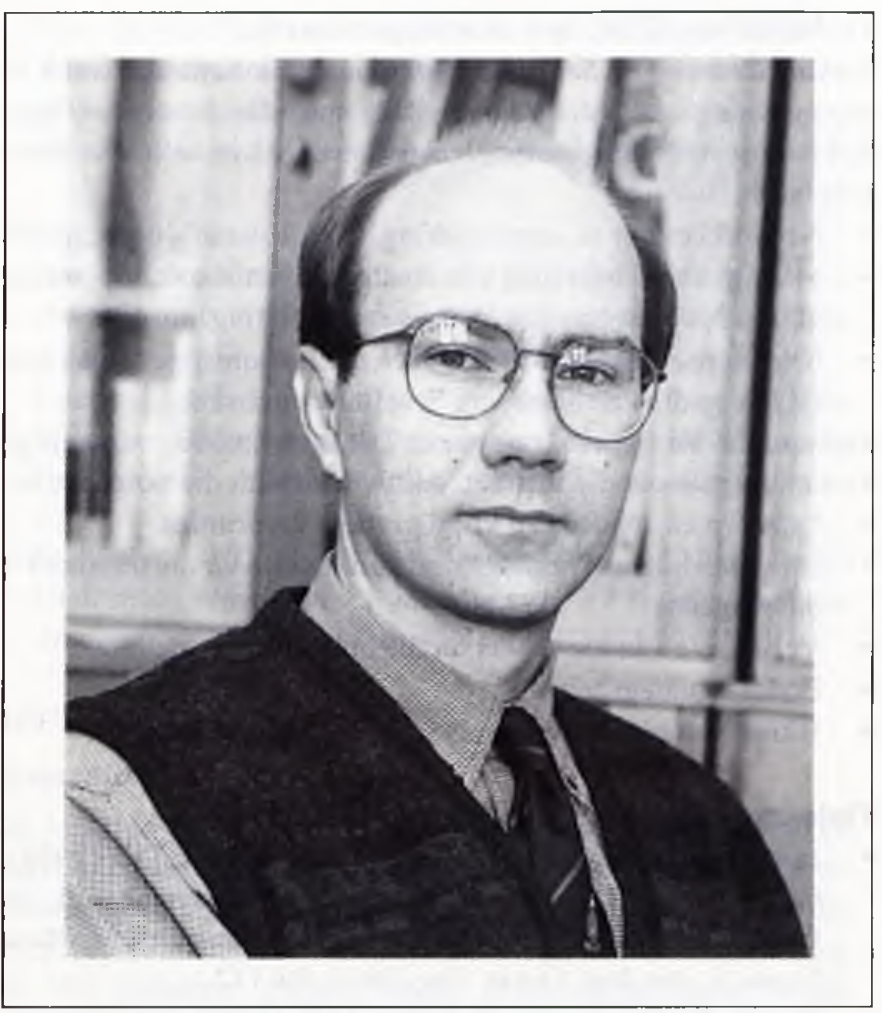

lan Craig is professor, navorsingsfunksiehoof en groephoof in die Departement Elektriese en Elektroniese Ingenieursivese aan die Universiteit van Pretoria. Hy het 'n B.Ing. (Elektronies)-graad aan die Universiteit van Pretoria hehaal, in SM van die Massachusetts Institute of Technology, in Ph.D.-graad in Elektriese Ingenieurswese, asook 'n MBA aan die Universiteit van die Witwatersrand. Prof Craig was voorheen groephoof in die Meet en Beheer Afdeling by Mintek en is die outeur of mede-outeur van ongeveer 30 joernaal- en konferensie-artikels. Hy is die president van die Suid-Afrikaanse Raad vir Outomatisasie en Berekening en dien op twee tegniese komitees van die International Federation of Automatic Control. Hy is ook as professionele ingenieur in Suid-Afrika geregistreer en is ' $n$ senior lid van die IEEE (The Institute of Electrical and Electronics Engineers) 